\title{
Model Transformasi Gelombang di Pelabuhan Patimban, Kabupaten Subang dengan Tiga Skenario
}

\author{
Rifka Pramesti Asa Rachmawatie*, Baskoro Rochaddi dan Elis Indrayanti \\ Departemen Oseanografi, Fakultas Perikanan dan IImu Kelautan, Universitas Diponegoro \\ JI. Prof.H.Soedarto S.H, Tembalang,Semarang, Jawa Tengah 50275 Indonesia \\ * Corresponding author, e-mail : rifkachika@student.undip.ac.id
}

\begin{abstract}
ABSTRAK: Pembangunan dermaga dan breakwater (pemecah gelombang) di Pelabuhan Patimban, Kabupaten Subang, Jawa Barat dapat mengakibatkan transformasi gelombang di perairan sekitarnya. Pemodelan transformasi gelombang penting untuk memberikan informasi sekaligus memprediksi seberapa besar pengaruh pembangunan dermaga dan breakwater terhadap perairan di sekitarnya. Tujuan dari penelitian adalah untuk mengetahui ada tidaknya transformasi gelombang dengan menggunakan tiga skenario. Penelitian lapangan dilaksanakan pada Januari sampai Februari 2020. Data yang digunakan adalah data gelombang hasil pengukuran lapangan, data angin, dan data batimetri. Peramalan gelombang dengan menggunakan metode SverdrupMunk Bretschneider (SMB). Pemodelan gelombang menggunakan model hidrodinamika untuk mengetahui besar transformasi gelombang. Tiga skenario yang digunakan yaitu skenario 1 (tanpa ada dermaga dan breakwater), skenario 2 (ada dermaga tanpa breakwater), dan skenario 3 (ada dermaga dan breakwater). Hasil simulasi menunjukan bahwa terjadi transformasi gelombang yang meliputi refraksi, refleksi, difraksi dan shoaling di Pelabuhan Patimban, dengan nilai koefisien refraksi tertinggi pada skenario 1. Penurunan tinggi gelombang terjadi pada skenario 2 dan skenario 3.
\end{abstract}

Kata kunci: transformasi gelombang, pemodelan gelombang, Pelabuhan Patimban.

\section{Wafe Transformation Model of Patimban Port Using Three Scenarios}

\begin{abstract}
The construction of a pier and breakwater at Patimban Port, Subang Regency, West Java can create wave transformation in the surrounding waters. Wave transformation modeling is important to provide information as well as predict how much influence the construction of the pier and breakwater will have effect on the surrounding waters. The purpose of this research is to determine the three scenarios effects for wave transformation. Field research was carried out from January to February 2020. The data used were wave data from field measurements, wind data, and bathymetry data. Wave forecasting using the Sverdrup-Munk Bretschneider (SMB) method. Wave modeling uses hydrodynamic models to determine the magnitude of the wave transformation. Three scenarios are used, namely scenario 1 (without a pier and breakwater), scenario 2 (there is a dock without a breakwater), and scenario 3 (there are a pier and breakwater). The simulation results show that there is a wave transformation which includes refraction, reflection, diffraction, and shoaling at Patimban Port, with the highest refraction coefficient value in scenario 1. A reduction in wave height occurs in scenarios 2 and scenario 3.
\end{abstract}

Keywords: wave transformation; wave modeling; Patimban Port

\section{PENDAHULUAN}

Pemerintah Indonesia melalui Peraturan Presiden Nomor 47 Tahun 2016 telah menetapkan pembangunan Pelabuhan Patimban sebagai proyek strategis nasional. Pelabuhan Patimban direncanakan sebagai pelabuhan utama yang berperan untuk kegiatan pelayaran nasional maupun internasional, serta sebagai penyangga Pelabuhan Tanjung Priok dan diharapkan dapat menekan biaya logistik Nasional (Wati dan Sakti, 2018; Wibowo dan Kongko; 2018). Pelabuhan merupakan 
suatu sentral ekonomi daerah yang dapat menghubungkan perpindahan muatan barang-barang produk kebutuhan sehari-hari baik dalam negeri maupun ekspor (Triatmodjo, 1996). Perencanaan pelabuhan dipengaruhi oleh tiga aspek penting, yaitu aspek politik, aspek ekonomi, dan aspek teknis. Dalam aspek teknis dibutuhkan tinjauan hidro-oseanografi yang terdiri atas tinjauan pelayaran, sedimentasi, dan gelombang (Triatmodjo ,2009).

Pembangunan Pelabuhan Patimban meliputi sejumlah fasilitas pelabuhan yang menunjang aktivitas pelabuhan, yaitu pembangunan dermaga dan breakwater. Pembangunan dermaga dan breakwater, akan berpengaruh terhadap proses hidrodinamika yang terjadi di perairan sekitarnya, antara lain perubahan karakteristik gelombang laut dan juga perubahan bentuk dan arah penjalaran gelombang itu sendiri. Menurut Cezalipi et al. (2017) terjadinya perubahan bentuk gelombang pada saat gelombang menjalar dari laut dalam menuju ke arah pantai karena adanya perubahan kedalaman laut. Perubahan gelombang tersebut disebut dengan transformasi gelombang. Gelombang mengalami perubahan cepat rambat, arah datang dan karakteristik tinggi gelombang (Hidayati, 2017). Transformasi gelombang memiliki pengaruh yang cukup besar terhadap tinggi dan arah gelombang serta distribusi energi gelombang di sepanjang pantai (Triatmodjo, 2009).

Bangunan laut juga merupakan salah satu alasan terjadinya perubahan penjalaran gelombang yang dapat menyebabkan perubahan bentuk gelombang. Dalam perencanaan tata letak dan tipe bangunan laut, data gelombang yang meliputi tinggi gelombang signifikan, tunggang pasang surut dan transformasi gelombang mejnjadi faktor yang sangat penting (Sugianto, et.al., 2012; Huda, et al., 2015). Oleh karena itu penelitian tentang transformasi gelombang akibat pembangunan dermaga dan breakwater ini perlu dilakukan. Informasi yang di dapat dalam penelitian ini berupa sudut datang, periode gelombang, dan tinggi gelombang dapat digunakan untuk mengetahui pergerakan energi gelombang dalam arah tegak lurus maupun sepanjang pantai.

\section{MATERI DAN METODE}

Materi yang digunakan dalam penelitian meliputi data primer dan data sekunder. Data primer berupa data hasil pengukuran langsung di lapangan yaitu data gelombang. Sedangkan, data sekunder merupakan data pendukung meliputi data batimetri dan hasil survey lapangan POC (Penta Ocean Contruction) dan PATIMONE CONSUL sebagai peta dasar, data angin dari ECMWF (European Center for Medium Range) selama 10 tahun (2010-2019) dan data rencana pembangunan Pelabuhan Patimban dari Kementrian Perhubungan Republik Indonesia.

Metode penelitian yang digunakan adalah metode survey untuk mendapatkan suatu data di tempat tertentu secara alamiah (Sugiyono, 2011). Penelitian ini terbagi menjadi lima tahapan yaitu penentuan lokasi penelitian, pengukuran data gelombang, pengolahan data angin, pengolahan data gelombang, peramalan gelombang, validasi, dan pemodelan gelombang.

Penentuan lokasi penelitian berada pada posisi -6 ${ }^{\circ} 20^{\prime} 1^{\prime \prime S} 107^{\circ} 88^{\prime} 3^{\prime \prime E},-6^{\circ} 20^{\prime} 1$ "S 107 $103^{\prime} 5^{\prime \prime E}$, $-6^{\circ} 25^{\prime} 1$ 'S $107^{\circ} 93^{\prime} 5 " \mathrm{E}$, dan $-6^{\circ} 25^{\prime} 1^{\prime \prime} \mathrm{S} 17^{\circ} 88^{\prime} 3^{\prime \prime} \mathrm{E}$ (Gambar 1). Pengukuran data gelombang pengukuran dengan menggunakan ADCP (Acoustic Doppler Current Profiler) yang diletakkan pada koordinat $109^{\circ} 8^{\prime} 10^{\prime \prime E}$ dan $6^{\circ} 50^{\prime} 37^{\prime \prime S}$ selama 30 hari pada kedalaman kurang lebih 10 meter di daerah sebelum gelombang pecah. Hasil pengukuran yang didapatkan berupa nilai tinggi gelombang $(\mathrm{H})$ dan periode gelombang $(T)$, serta sudut datang gelombang $(\alpha)$.

Penentuan arah angin menggunakan software WRplot. Arah angin digolongkan permusim terlebih dahulu guna mempermudah dalam proses analisis. Pengelompokan berupa musim barat (Desember - Februari), musim peralihan I (Maret - Mei), musim timur (Juni - Agustus), musim peralihan II (September - November). Data angin yang sudah di kelompokkan kemudian di olah menggunakan WRplot view untuk memperoleh hasil kondisi dominan angin yang akan di sajikan dalam mawar angin (windrose).

Pengolahan data gelombang lapangan menggunakan metode penentuan gelombang representative (Triatmodjo, 2008). Dari data yang di dapat, diukur data dari yang tertinggi sampai terendah kemudian dilakukan perhitungan parameter gelombang representatif yaitu gelombang signifikan (Hs).

$$
\begin{aligned}
& \mathrm{N}=33,3 \% \mathrm{X} \text { jumlah data } \\
& \mathrm{Hs}=\frac{h 1+h 2+\cdots+h n}{n}
\end{aligned}
$$




$$
\mathrm{TS}=\frac{T 1+T 2+\cdots+T n}{n}
$$

Keterangan : Hs : Tinggi gelombang signifikan $(m)$, Ts : Periode gelombang signifikan (dt), h1,h2 : Urutan tinggi gelombang $(\mathrm{m}), \mathrm{T} 1, \mathrm{~T} 2$ : Urutan periode gelombang (dt)

Peramalan Gelombang menggunakan metode Sverdrup, Munk, and Bretschneider (CERC, 1987), untuk mengetahui nilai transformasi gelombang. Data yang digunakan adalah data angin selama 10 tahun (2010 - 2019). Validasi dari hasil peramalan gelombang didapatkan tinggi gelombang $(\mathrm{H})$ dan periode gelombang $(\mathrm{T})$, kemudian dilakukan verifikasi data dengan metode Mean Relative Error (MRE), yakni untuk mengetahui kemiripan hasil peramalan gelombang dan data pengamatan di lapangan. Metode ini digunakan untuk mengetahui kemiripan data lapangan dengan model yang dihasilkan. Model dianggap valid jika nilai MRE kurang dari $10 \%$ (Setiawan et al., 2018; Rezagama et al., 2019). Persamaan yang digunakan sebagai berikut:

$$
\text { MRE }=\frac{\text { Hs peramalan }- \text { Hs lapangan } \mid}{\mid \text { Hs lapangan } \mid} \times 100 \%
$$

Pemodelan gelombang menggunakan model hidrodinamika dengan tiga skenario yang dijalankan pada tiap musim, sebagai berikut : Skenario 1 : tanpa ada dermaga dan breakwater merupakan kondisi awal pelabuhan; Skenario 2 : ada dermaga (tanpa breakwater) yang merupakan kondisi pembangunan pelabuhan tahap pertama yang saat ini sedang berlangsung di Pelabuhan Patimban; Skenario 3 :ada dermaga dan breakwater. Inputan model adalah data maksimum parameter gelombang dari hasil peramalan SMB, yaitu tinggi gelombang signifikan (Hs), periode gelombang signifikan (Ts), arah pembangkit gelombang yang ada tiap musimnya serta data batimetri.

\section{HASIL DAN PEMBAHASAN}

Tinggi dan periode gelombang signifikan yang diperoleh dari hasil pengukuran lapangan adalah $0.254 \mathrm{~m}$ dan $4.244 \mathrm{dt}$. Grafik tinggi dan periode gelombang selama pengukuran pada Gambar 2 .

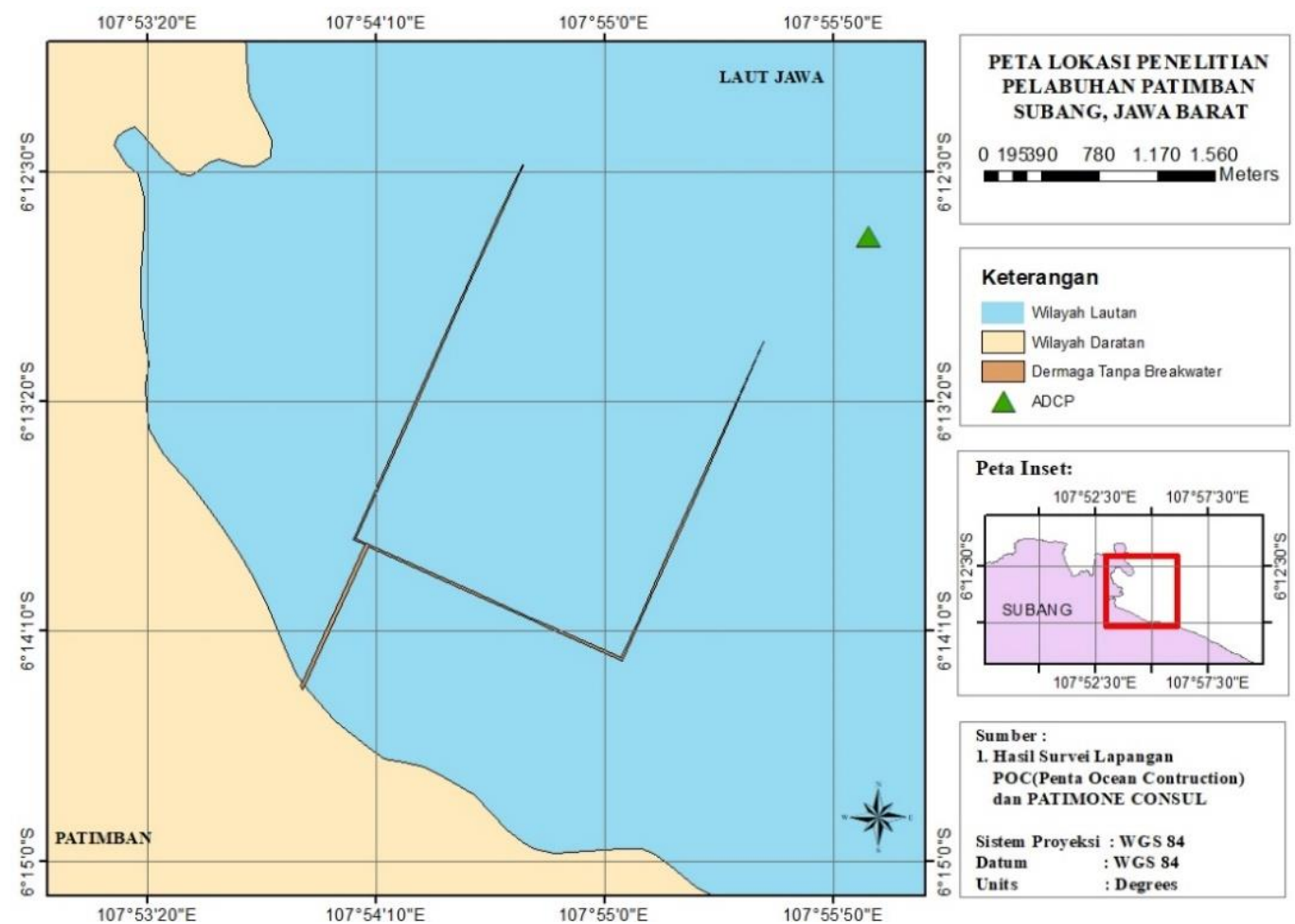

Gambar 1. Lokasi Penelitian Pelabuhan Patimban, Subang, Jawa Barat. 

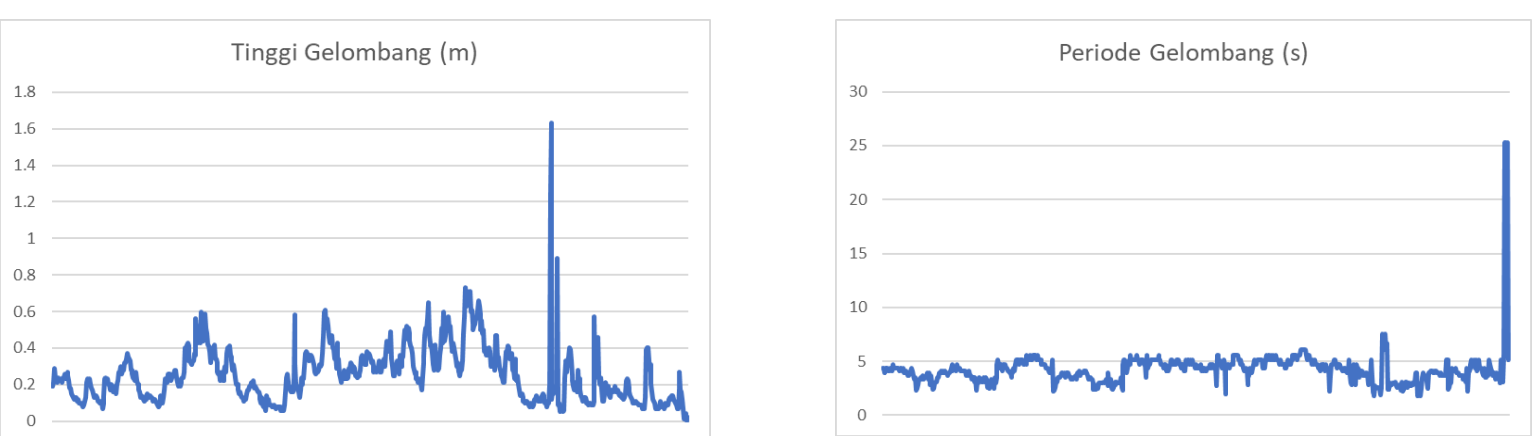

Gambar 2. Grafik Tinggi dan Periode Gelombang Hasil Pengukuran Lapangan

Data Angin : hasil pengolahan data angin disajikan setiap musim dalam bentuk mawar angin (Gambar 3). Pada musim barat angin dominan berasal dari arah utara dengan kecepatan antara 711 knots dan presentase sebesar $42.2 \%$. Musim peralihan I, angin dominan berasal dari arah selatan dengan kecepatan 7-11 knots dan presentase sebesar $18.7 \%$. Sedangkan pada musim timur angin dominan berasal dari arah selatan dengan kecepatan 7-11 knots dan presentase sebesar $37.7 \%$. Pada musim peralihan II angin dominan berasal dari arah tenggara dengan kecepatan 1-4 knots dan presentase sebesar $21.3 \%$. Hasil yang diperoleh pada musim barat dan musim peralihan I, sesuai dengan penelitian sebelumnya yang dilakukan oleh Cezalipi et al., (2017) di Pelabuhan Patimban. Sedangkan untuk arah angin terdapat sedikit pernedaan pada musim timur, yaitu arah dominan berasal dari arah tenggara sedangkan pada hasil penelitian ini dominan dari arah selatan. dengan kecepatan dominan 7-11 knots dan presentase sebaran $39.18 \%$.

Hasil yang diperoleh diduga berkaitan erat dengan angin monsoon. Menurut Pusparini (2015), angin monsoon merupakan angin yang berbalik arah secara musiman, yang disebabkan oleh perbedaan sifat termal antara benua dan lautan. Pada musim barat dengan kondisi arah dominan pada arah resultan utara $\left(\mathrm{N} 348^{\circ} \mathrm{E}\right)$ sedangkan musim timur dengan kondisi arah dominan arah selatan $\left(\mathrm{N} 180^{\circ} \mathrm{E}\right)$ yang terjadi secara musiman. Sedangkan pada musim peralihan I dan musim peralihan II, hasil data angin menjadi bervariasi dengan kecepatan angin yang rendah dimana nilai persistensi angin yang rendah menandakan bahwa arah angin yang berhembus dengan kemungkinan yang sama dari segala arah.

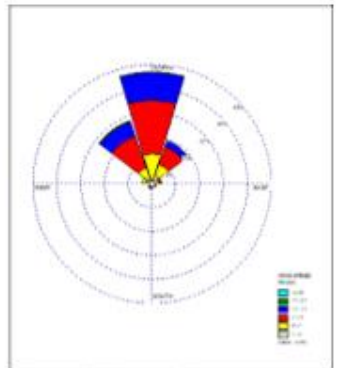

(a) Musim Barat

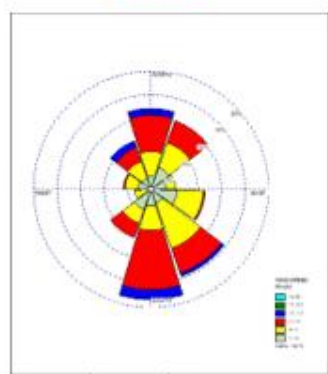

(b) Musim Reralihan I

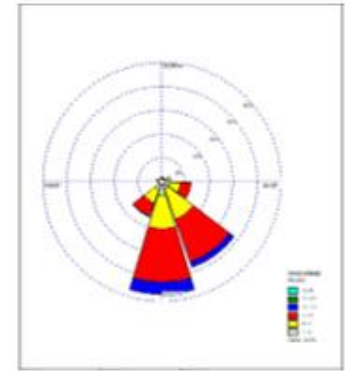

(c) Musim Timur

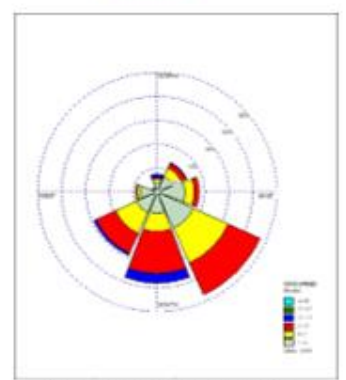

(d) Musin Peraliban II

Gambar 3. Arah Angin Dominan Tiap Musim 
Peramalan gelombang Tinggi dan periode gelombang hasil peramalan dengan metode SMB berdasarkan musim yang terjadi pada tahun 2010 - 2019 dapat dilihat pada Tabel 1 dan Tabel 2.

Validasi Data Gelombang berdasarkan hasil data gelombang yang di dapat dari pengukuran kemudian dilakukan proses validasi dengan menggunakan metode RMSE yaitu tinggi gelombang sebesar - $0.326 \%$ dan periode gelombang sebesar - $0.544 \%$. Berdasarkan nilai RMSE menunjukkan bahwa nilai tinggi gelombang dan periode gelombang memiliki tingkat akurasi yang berbeda namun telah dianggap valid karena memiliki hasil yang kurang dari $10 \%$ menurut Rezagama (2019). Tabel 3 menunjukkan hasil perbandingan pengukuran lapangan dengan pemodelan.

Perbandingan Tinggi Gelombang Hasil Pemodelan perbandingan hasil pemodelan gelombang dilakukan dengan mengambil 6 titik pengamatan yang berbeda (Gambar 4, 5 dan 6) pada tiga skenario pemodelan dan pada setiap musim (Tabel 4,5,6 dan 7). Hasil perhitungan menunjukkan adanya penurunan tinggi gelombang pada skenario 2 dan 3 dengan adanya dermaga/breakwater. Pemodelan Gelombang hasil pemodelan gelombang dengan 3 skenario pada tiap musim disajikan pada Gambar 4, 5 dan 6. Berdasarkan hasil pemodelan yang di dapatkan pada tiga skenario yang berbeda, menunjukkan bahwa dalam musim yang berbeda menghasilkan karakteristik gelombang yang berbeda.

Tabel 1. Tinggi Gelombang Angin Periode 2010 - 2019

\begin{tabular}{lcccc}
\hline & \multicolumn{4}{c}{ Tinggi Gelombang (meter) } \\
\cline { 2 - 5 } & Min & Max & Rata - Rata & Signifikan \\
\hline Musim Barat & 0.00050 & 1.45129 & 0.22386 & 0.67836 \\
Musim Peralihan I & 0.00015 & 1.44892 & 0.19805 & 0.60015 \\
Musim Timur & 0.00012 & 1.44797 & 0.06909 & 0.20935 \\
Musim Peralihan II & 0.00004 & 1.45217 & 0.12174 & 0.36892 \\
\hline
\end{tabular}

Tabel 2. Periode Gelombang Angin Periode 2010 - 2019

\begin{tabular}{lccrc}
\hline & \multicolumn{4}{c}{ Periode Gelombang (detik) } \\
\cline { 2 - 5 } & Min & Max & Rata - Rata & Signifikan \\
\hline Musim Barat & 0.11817 & 6.34273 & 1.55858 & 4.72298 \\
Musim Peralihan I & 0.06460 & 6.33753 & 1.52321 & 4.61579 \\
Musim Timur & 0.05760 & 6.33547 & 0.77260 & 2.34122 \\
Musim Peralihan II & 0.03462 & 6.34465 & 1.12853 & 3.41979 \\
\hline
\end{tabular}

Tabel 3. Perbandingan Pengukuran Data Lapangan dan Data Peramalan

\begin{tabular}{cccc}
\hline \multicolumn{2}{c}{ Pengukuran Data Lapangan } & \multicolumn{2}{c}{ Peramalan Data Gelombang } \\
Hs & Ts & Hs & Ts \\
\hline 0.254528 & 4.244226 & 0.171422 & 1.931376 \\
\hline
\end{tabular}

Tabel 4. Perbandingan Tinggi Gelombang Pada Musim Barat

\begin{tabular}{crrrrrr}
\hline & \multicolumn{7}{c}{ Tinggi Gelombang $(\mathrm{m})$} \\
\cline { 2 - 6 } Skema & Titik 1 & Titik 2 & Titik 3 & Titik 4 & Titik 5 & Titik 6 \\
\hline Skenario 1 & 0,0324 & 0,0779 & 0,1187 & 0,1568 & 0,0808 & 0,2616 \\
Skenario 2 & 0,0305 & 0,0001 & 0,0029 & 0,1443 & 0,0006 & 0,2630 \\
Skenario 3 & 0,0395 & 0,0000 & 0,0001 & 0,0985 & 0,0007 & 0,2521 \\
\hline
\end{tabular}


Perhitungan Analitik Nilai Koefisien Refraksi (Kr) dan Koefisien Pendangkalan (Ks) untuk mengetahui nilai $\mathrm{Kr}$ dan $\mathrm{Ks}$ maka dilakukan analisa dengan mengambil 6 titik pengamatan yang berbeda pada setiap skenario pemodelan. Hasil perhitungan tersaji pada Tabel 8 dan 9.

Tabel 5. Perbandingan Tinggi Gelombang Pada Musim Peralihan I

\begin{tabular}{crrrrrr}
\hline & \multicolumn{5}{c}{ Tinggi Gelombang $(\mathrm{m})$} \\
\cline { 2 - 6 } Skema & Titik 1 & Titik 2 & Titik 3 & Titik 4 & Titik 5 & Titik 6 \\
\hline Skenario 1 & 0,5466 & 0,5643 & 0,5700 & 0,5974 & 0,5609 & 0,5767 \\
Skenario 2 & 0,0028 & 0,4910 & 0,5640 & 0,5975 & 0,5362 & 0,5707 \\
Skenario 3 & 0,0020 & 0,1299 & 0,3033 & 0,6010 & 0,5885 & 0,5705 \\
\hline
\end{tabular}

Tabel 6. Perbandingan Tinggi Gelombang Pada Musim Timur

\begin{tabular}{ccccccc}
\hline & \multicolumn{5}{c}{ Tinggi Gelombang $(\mathrm{m})$} \\
\cline { 2 - 6 } Skema & Titik 1 & Titik 2 & Titik 3 & Titik 4 & Titik 5 & Titik 6 \\
\hline Skenario 1 & 0,2141 & 0,2131 & 0,2080 & 0,2069 & 0,2073 & 0,2068 \\
Skenario 2 & 0,0014 & 0,1819 & 0,2125 & 0,2126 & 0,1882 & 0,2129 \\
Skenario 3 & 0,0002 & 0,0535 & 0,1143 & 0,2004 & 0,2003 & 0,2003 \\
\hline
\end{tabular}
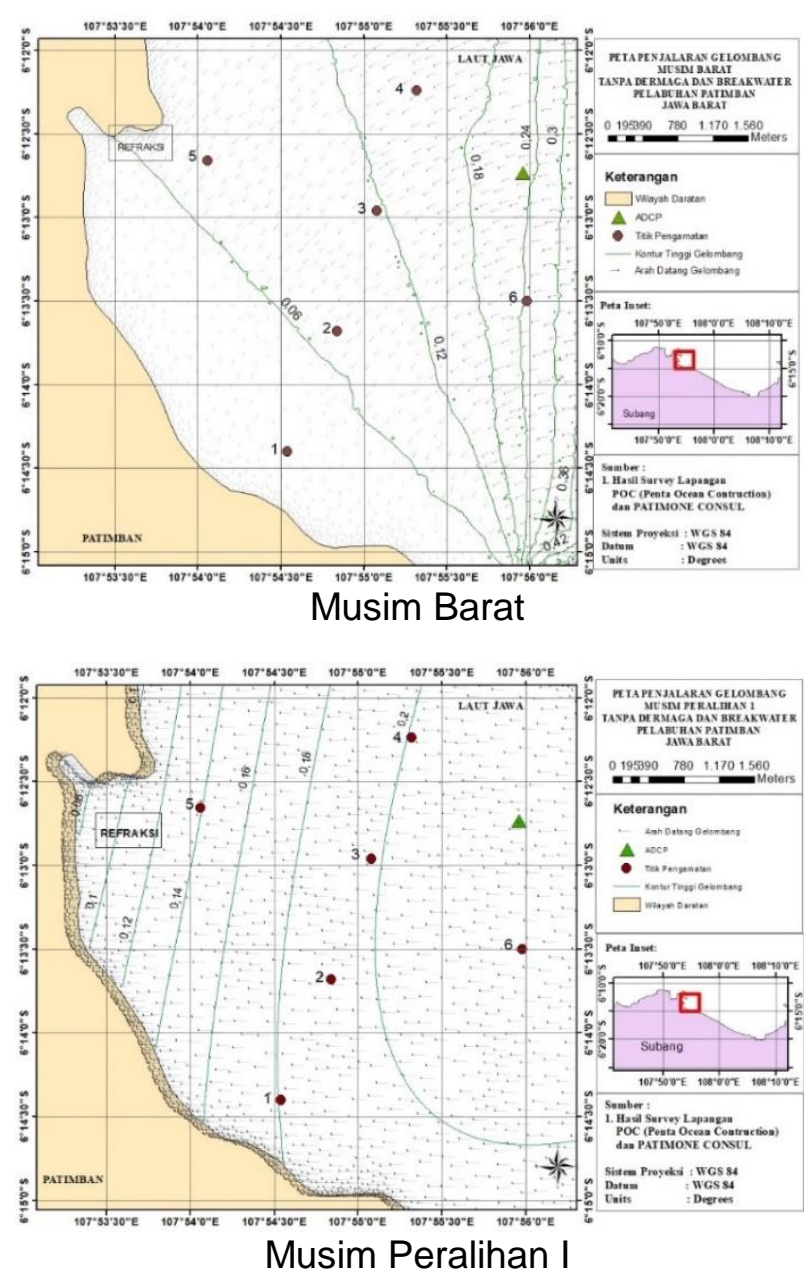

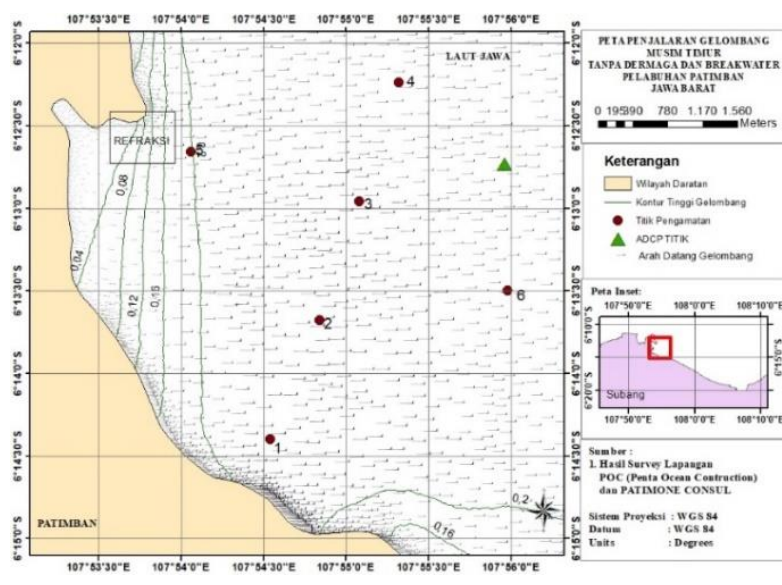

Musim Timur

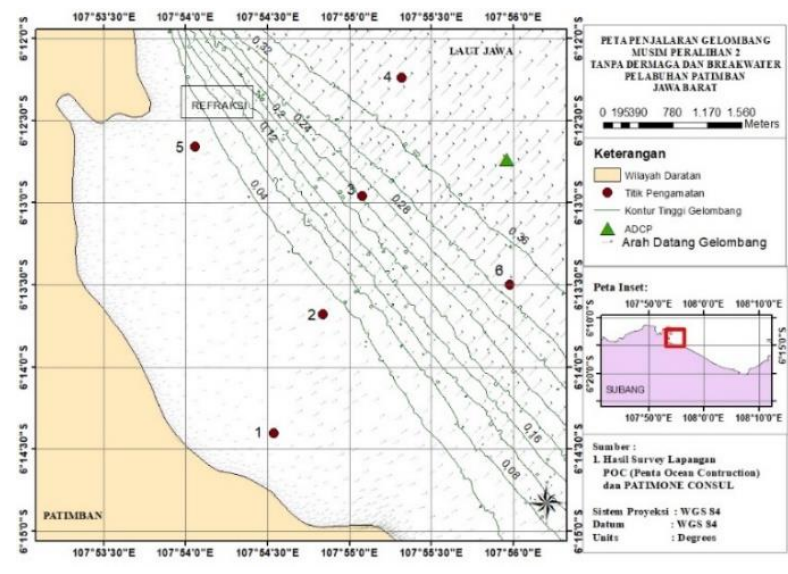

Musim Peralihan II

Gambar 4. Skenario 1 - Tanpa Dermaga dan Breakwater 
Skenario 1 - Proses refraksi gelombang dapat diamati secara jelas dalam skenario pertama dimana gelombang yang terjadi di sekitar pelabuhan mengalami pembelokan arah penjalaran. Pada proses refraksi maka arah gelombang terus melaju mendekati pantai dan cenderung tegak lurus terhadap garis kontur dasar laut sampai mendekati pantai, karena adanya pendangkalan pada dasar laut dekat pantai (Samulano dan Mera, 2011). Fenomena ini terlihat jelas pada musim barat (Gambar 4), yaitu arah datang gelombang dominan dari arah utara, akibat adanya perubahan kontur kedalaman perairan menyebabkan muka gelombang datang cenderung dibelokkan dan sejajar dengan garis pantai. Garis sinar gelombang berusaha untuk tegak lurus dengan kontur kedalaman. Proses refraksi gelombang juga dapat di amati pada perhitungan analitik koefisien refraksi pada tabel 4. Nilai yang didapat pada perhitungan analitik di tiga skenario dan di amati pada 6 titik pengamatan menunjukkan adanya peristiwa refraksi gelombang. Peristiwa refraksi paling tinggi dilihat dari hasil perhitungan berada pada keadaan tanpa dermaga dan breakwater (skenario 1). Proses shoaling atau pendangkalan teramati secara jelas pada skenario pertama, dengan adanya peristiwa gelombang yang menuju ke perairan dangkal yang mengakibatkan adanya perubahan tinggi gelombang. Perhitungan analitik koefisien pendangkalan pada Tabel 5 dan Gambar 4 menunjukkan adanya peristiwa shoaling.

Skenario 2 - Proses refleksi gelombang dapat diamati secara jelas dalam skenario kedua yaitu penjalaran gelombang dengan dermaga tanpa breakwater, menunjukkan adanya peristiwa pemantulan gelombang. Proses terjadinya refleksi nampak terlihat pada Gambar 5, diperlihatkan dengan adanya garis sinar gelombang menuju dermaga dan kemudian dipantulkan kembali menjauhi dermaga. Tinjauan mengenai refleksi gelombang sangat penting dilakukan dalam perencanaan pelabuhan. Refleksi gelombang di dalam pelabuhan akan menyebabkan ketidaktenangan yang terjadi di dalam perairan pelabuhan, seperti yang dapat dilihat pada pemodelan gelombang musim timur pada skenario kedua (Gambar 5). Dengan adanya proses refleksi gelombang yang terjadi di wilayah dekat dermaga, maka diperlukan adanya bangunan yang mampu menghancurkan energi gelombang di wilayah tersebut.

Tabel 7. Perbandingan Tinggi Gelombang Pada Musim Peralihan II

\begin{tabular}{ccccccc}
\hline & \multicolumn{5}{c}{ Tinggi Gelombang $(\mathrm{m})$} \\
\cline { 2 - 6 } Skema & Titik 1 & Titik 2 & Titik 3 & Titik 4 & Titik 5 & Titik 6 \\
\hline Skenario 1 & 0,0094 & 0,0278 & 0,2547 & 0,3692 & 0,0187 & 0,3365 \\
Skenario 2 & 0,0001 & 0,0036 & 0,1200 & 0,3677 & 0,0016 & 0,1999 \\
Skenario 3 & 0,0000 & 0,0001 & 0,0014 & 0,3608 & 0,0158 & 0,0599 \\
\hline
\end{tabular}

Tabel 8. Perhitungan Analitik Koefisien Refraksi

\begin{tabular}{lrrrrrr}
\hline & \multicolumn{7}{c}{ Titik Pengamatan } \\
\cline { 2 - 7 } & 1 & 2 & 3 & 4 & 5 & 6 \\
\hline Skenario 1 & 0,87532 & 1,21051 & 1,14861 & 0,93089 & 1,02696 & 0,97609 \\
Skenario 2 & 0,59557 & 0,87503 & 0,87504 & 0,87522 & 0,52469 & 0,78483 \\
Skenario 3 & 0,87538 & 0,97544 & 0,87544 & 0,87525 & 1,45862 & 0,97614 \\
\hline
\end{tabular}

Tabel 9. Perhitungan Analitik Koefisien Pendangkalan

\begin{tabular}{lccccrr}
\hline & \multicolumn{7}{c}{ Titik Pengamatan } \\
\cline { 2 - 7 } & 1 & 2 & 3 & 4 & 5 & 6 \\
\hline Skenario 1 & 5,64478 & 6,42906 & 7,22645 & 10,2264 & 7,38192 & 9,62311 \\
Skenario 2 & 5,58981 & 4,37434 & 4,44712 & 9,96638 & 5,01851 & 9,62330 \\
Skenario 3 & 4,80313 & 4,37358 & 4,36609 & 8,80821 & 5,02101 & 9,61221 \\
\hline
\end{tabular}



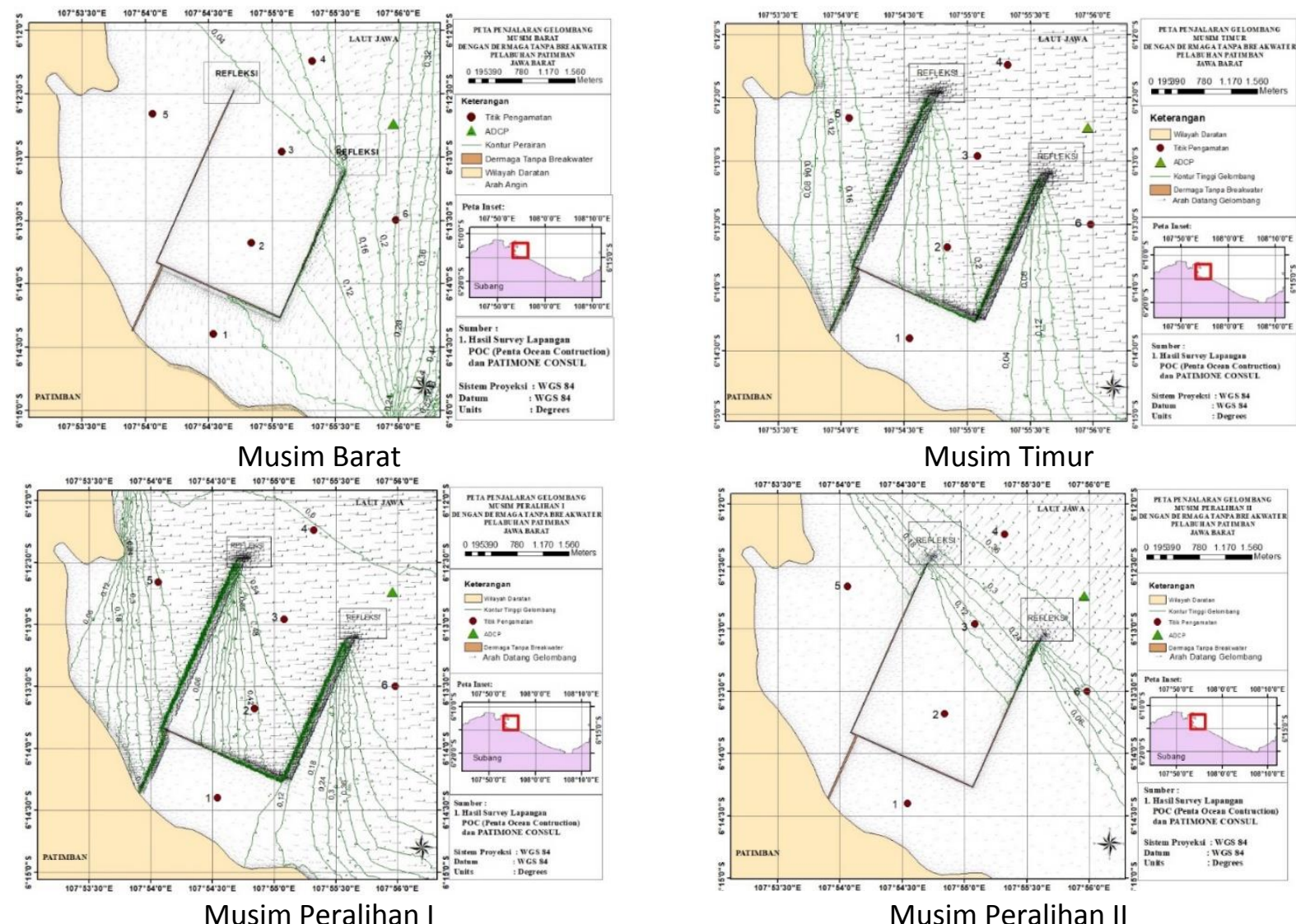

Musim Peralihan

Musim Peralihan II

Gambar 5. Skenario 2 - Ada Dermaga dan Tanpa Breakwater
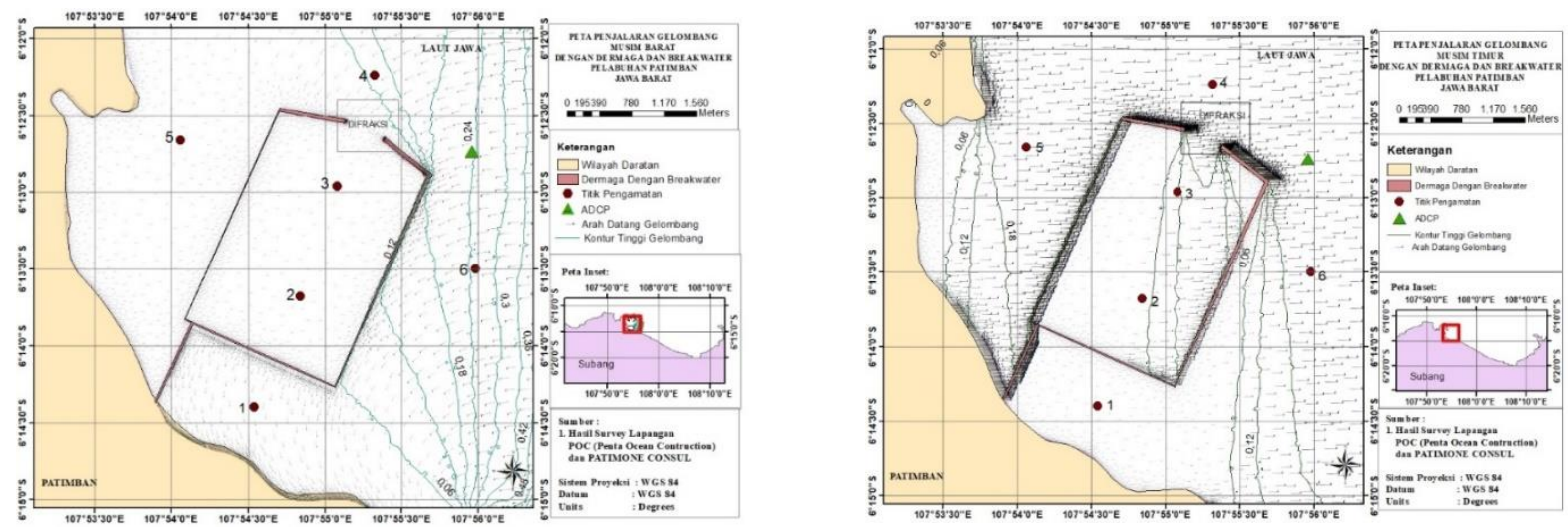

Musim Barat

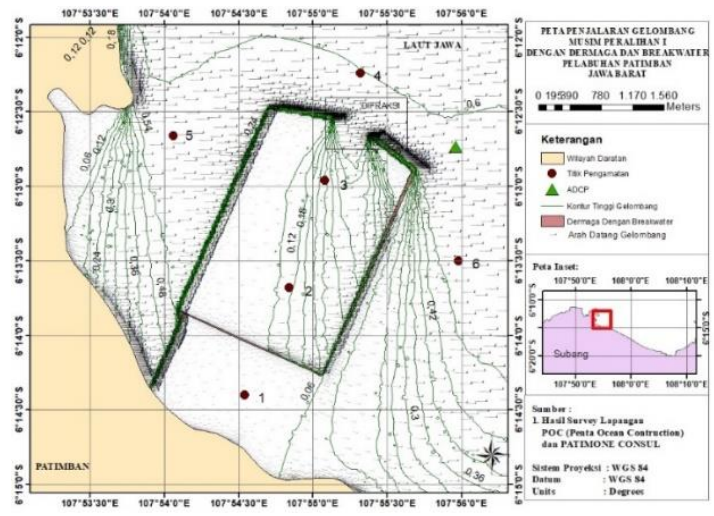

Musim Peralihan I

Musim Timur

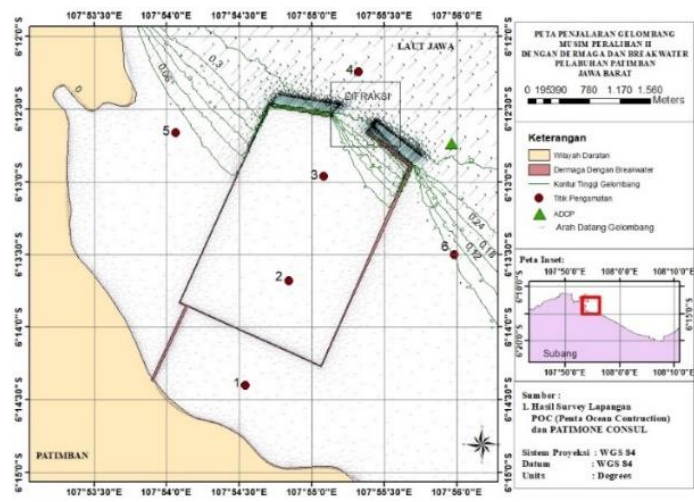

Musim Peralihan II

Gambar 6. Skenario 3 - Ada Dermaga dan Breakwater 
Skenario 3 - Proses difraksi gelombang dapat diamati secara jelas dalam skenario ketiga (Gambar 6). Adanya penghalang (breakwater) yang berada di kanan dan kiri dermaga menyebabkan gelombang datang menabrak penghalang, kemudian masuk kedalam daerah yang terlindungi dan mengakibatkan tinggi gelombang menjadi berkurang. Hal ini nampak pada hasil perhitungan dalam Tabel 4,5,6,7 dimana secara keseluruhan terjadi adanya penurunan tinggi gelombang dengan adanya penambahan bangunan (dermaga atau breakwater). Berdasarkan hasil penelitian Jade, et.al., (2018) diperoleh bahwa gelombang (mencapai tinggi 1,5 meter) dan sedimentasi merupakan faktor penting dalam mempertimbangkan pemilihan jenis bangunan pelindung pantai di Perairan Patimban. Gelombang yang tinggi dapat membahayakan kapal yang akan memasuki dermaga/pelabuhan, dengan adanya breakwater yang berfungsi sebagai pemecah gelombang diharapkan mampu meredam tinggi gelombang sehingga nantinya tidak membahayakan pelayaran kapal di wilayah Pelabuhan Patimban.

\section{KESIMPULAN}

Hasil pemodelan transformasi gelombang dengan tiga skenario menunjukkan adanya proses transformasi yang terjadi di Pelabuhan Patimban yaitu refraksi, refleksi, difraksi dan shoaling. Peristiwa refraksi dan shoaling tertinggi berdasarkan hasil perhitungan koefisien refraksi (Ks) dan koefisien pendangkalan (Ks) terjadi pada skenario 1 yaitu kondisi pelabuhan tanpa dermaga dan breakwater. Secara keseluruhan terjadi penurunan tinggi gelombang baik pada skenario 2 yaitu kondisi pelabuhan dengan dermaga, maupun pada skenario 3 yaitu kondisi pelabuhan dengan dermaga dan breakwater.

\section{UCAPAN TERIMAKASIH}

Terima kasih kepada POC (Penta Ocean Contruction), PATIMONE CONSUL dan Kementerian Perhubungan Direktorat Jendral Perhubungan Laut Kantor Kesyahbandaran dan Otoritas Pelabuhan Kelas II Patimban atas ijin untuk penelitian, data dan bantuan selama pengambilan data lapangan.

\section{DAFTAR PUSTAKA}

Central Engineering Research Center (CERC). 1987. Shore Protection Manual Volume I. Departement Of The Army Waterways Experiment Station, Corps Of Engineers, Washington DC.

Cezalipi, J., Prasetyawan, I.B. \& Marwoto, J. 2017. Kajian Karakterisitik Gelombang Laut Akibat Pengaruh Rencana Pembangunan Pelabuhan Patimban, Subang. Jurnal Oseanografi, 6(3): 475-484

Hidayati, N. 2017. Dinamika Pantai. UB Press. Malang.

Huda, A.N., Suryoputro, A.A.D. \& Subarbjo, P. 2015. Studi Pola Transformasi Gelombang Di Perairan Kota Tegal. Jurnal Oseanografi, 4(1):341-349

Jade, R.R., Perbani, N.M.R.R.C. \& Handiani, D.N., 2017. Analisis Efektivitas Bangunan Pelindung Pelabuhan Patimban dan Pantai Sekitar Melalui Tinjauan Hidro-Oseanografi. Reka Geomatika, 2:102-112.

Keputusan Menteri Perhubungan Republik Indonesia Nomor KP 180 .2017. Penetapan Lokasi Pelabuhan Laut Utama Patimban di Desa Patimban, Kecamatan Pusakanegara, Kabupaten Subang, Provinsi Jawa Barat. Menteri Perhubungan Republik Indonesia.

Pusparini, N., Winardi, T.B. \& Irmawan, D., 2015. Analisa Angin Zonal Dalam Menentukan Awal Musim Hujan Di Bali Bagian Selatan. Buletin Fisika, 16(2):7-15.

Setiawan, A.D., Widyastuti, M. \& Hadi, M.P. 2018. Water Quality Modeling for Pollutant Carrying Capacity Assessment using Qual2Kw in Bedog River. Indonesian Journal of Geography, 50(1):49-56

Rezagama, A. Sarminingsih, A. Rahmadhani, A.Y. \& Aini, A.N. 2019. Pemodelan Peningkatan Kualitas Air Sungai melalui Variasi Debit Suplesi. Teknik,40(2):106-114

Samulano, I \& Mera, M..2011. Refraksi Dan Difraksi Gelombang Laut Di Daerah Dekat Pantai Pariaman. Jurnal Rekayasa Sipil, 7(1):1-10. 
Sugianto, D.N., Purwanto, \& Candra, A.B.. 2015. Wave Transformation for International Hub Port Planning (Transformasi Gelombang untuk Perencanaan Pelabuhan Hub Internasional). IImu Kelautan : Indonesian Journal of Marine Sciences, 20(1):9-22.

Sugiyono. 2011.Metode Penelitian Kuantitatif Kualitatif dan R\&D. Alfabeta, Bandung.

Triatmodjo, B. 2009. Perencanaan Pelabuhan. Beta Offset, Yogyakarta.

Wati, W., \& Sakti, W.I. 2018. Analisis Perancangan Struktur Organisasi Penyelenggaraan Proyek Pembangunan Pelabuhan Patimban. Jurnal Muara, 2(2):381-392.

Wibowo, M., \& Kongko, W. 2018. Kajian Pengaruh Dike untuk Mengendalikan Proses Sedimentasi di Rencana Pelabuhan Patimban Menggunakan Pemodelan Komputasi. Majalah Ilmiah Pengkajian Industri, 12(2):85-96. 